\title{
Relapses in Leprosy after Release from Control
}

\author{
E. M. J. TOUW-LANGENDIJK and B. NAAFS \\ All Africa Leprosy and Rehabilitation Training Centre (ALERT), \\ P. O. Box 165, Addis Ababa, Ethiopia
}

\begin{abstract}
In 1974, 678 patients, originally classified as suffering from various types of leprosy from LL to TT, were released from control. During the next 3 years, 105 of them reported back on their own accord, with evidence of relapse which was confirmed by clinical, bacteriological and electrophysiological observations. During this period the overall relapse rate was $15 \%$, but patients in the LL/BL group, the indeterminate group, and the BT group treated for less than 5 years, had a relapse rate of over $30 \%$. Reasons for these disconcertingly high figures are discussed and a plea is made for the collection of more data on relapse rates in similar groups of patients from different countries, in order to revise the criteria for releasing patients from treatment.
\end{abstract}

\section{Introduction}

Since the introduction of dapsone in the treatment of leprosy, both the dose and duration of treatment have changed considerably. In the early years of treatment dapsone was stopped immediately when a state of inactivity was achieved. However, a large relapse rate was encountered (Erickson, 1950; Rodriguez, 1958) and it soon became evident that even after clinical arrest of the disease continuation of treatment was necessary (Cochrane and Davey, 1964), the duration of treatment after inactivity being dependent on the original classification of the patient.

At present (1977) WHO continues to advise treatment for tuberculoid patients at least $1 \frac{1}{2}$ years after inactivity, for indeterminate patients, 3 years after inactivity, and for borderline-lepromatous (BL) and lepromatous cases, 10 years after this state is achieved, or maybe even better on a life-time basis in the last two categories. Dharmendra (1976) has reviewed the important and difficult matter of length of treatment after inactivity, with conclusions which are similar in principle.

In this study we checked the clinical records of 678 patients suffering from various forms of leprosy, who were released from control (RFC) in 1974. The number of relapses in the following 3 years, the cause, and the seriousness of the relapses are studied. 


\section{Patients and Methods}

Clinical records of patients who were released from control in 1974 were reviewed. The original classification according to Ridley and Jopling (1966), biopsy results and skin smears were recorded. Dapsone treatment and dose were noted. Before 1974, patients were usually treated with $300 \mathrm{mg}$ DDS in a single weekly dose, this being gradually achieved over a period of 3-6 months. When a reaction occurred, or when a patient defaulted for a longer or shorter period, the treatment was initiated again with low doses.

During their treatment period these patients, all living in Addis Ababa, attended regularly, and every half year their progress was recorded in the clinical records. In 1974, 678 of them were released from control and dapsone was stopped. After RFC there was no regular follow-up of the patients, but those who suspected that their disease had come back, reported on their own initiative to the hospital. The method of detection and confirmation of relapse are shown in Table 1 .

TABLE 1

\begin{tabular}{ll}
\hline Signs of relapse & Method of detection \\
\hline (1) New skin lesions & Clinical examination and biopsy \\
(2) New numbness of extremities & Sensory testing \\
(3) New paralysis & Voluntary muscle testing \\
(4) Tenderness of nerves & Clinical examination and \\
(5) Presence of leprosy bacilli & electromyography \\
\hline
\end{tabular}

\section{Results}

From the 678 patients who were RFC in 1974, 105 patients reported with proven signs of relapse. Many others have been seen with general complaints including fear of relapse. Of the 105 patients, many had to report more than once before relapse could be confirmed.

Table 2 presents the relapse rate according to the original classification. It can be seen that 3 groups especially have a very high relapse rate in this 3 -year period: the $\mathrm{BL} / \mathrm{LL}$ group, the indeterminate group and the BT group treated for less than 5 years, have a relapse rate of over $30 \%$. In the other groups the relapse rate is lower than a more or less acceptable $15 \%$.

A large number of patients came with new nerve involvement as the first sign of relapse. Figure 1 shows the cumulative number of relapsed patients according to the time after RFC, and the cumulative number of patients who relapsed with nerve damage.

This figure shows: (1) that from the 105 patients who relapsed, 48 patients (46\%) did so with new nerve damage: anaesthesia, palsy and neuritis; (2) year by year, the relative number of patients relapsing with nerve damage is $40 \%$ of 
TABLE 2

Classification, number and percentage of relapses in 105 patients reporting back within 3 years of release from control $(R F C)$

\begin{tabular}{|c|c|c|c|}
\hline \multirow[b]{2}{*}{ Classification } & \multirow{2}{*}{$\begin{array}{l}\text { Number of } \\
\text { patients }\end{array}$} & \multicolumn{2}{|c|}{ Relapses } \\
\hline & & Number & Percentage \\
\hline $\mathrm{TT}$, treated for at least $1 \frac{1}{7}$ years & 239 & 33 & $14 \%$ \\
\hline $\mathrm{BT}$, treated for at least 5 years & 204 & 31 & $15 \%$ \\
\hline BT, treated for less than 5 years & 50 & 14 & $28 \%$ \\
\hline \\
\hline after inactivity & 37 & 12 & $32 \%$ \\
\hline Indete & 27 & 8 & $30 \%$ \\
\hline Classification not known; treated for more & 121 & 7 & $6 \%$ \\
\hline TOTAL & 678 & 105 & $15 \%$ \\
\hline
\end{tabular}

the total number of relapsed patients; (3) the majority of the patients relapse within 2 years after RFC, but relapses can be expected for a much longer period.

\section{Discussion}

Within 3 years, $15 \%$ of the patients RFC came back to the hospital with signs of active leprosy. This relapse rate is slightly higher than reported by other authors (Browne, 1965; Kandaswamy, 1968; Ramu and Ramanujam,

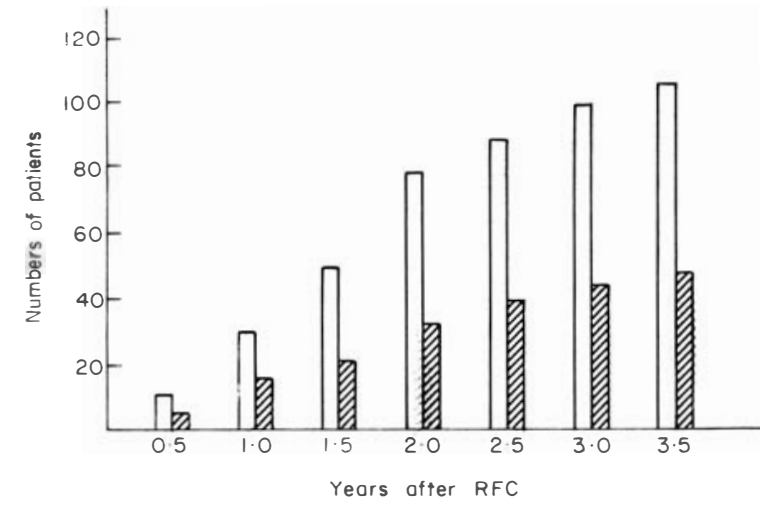

Fig. 1 
1974). It must be borne in mind that the actual percentage may be higher, since many patients may not have reported with their relapse. We believe that overdiagnosing of relapse in this study has been avoided by adhering to a definite set of criteria (Table 1).

The cause of relapse may be a reinfection, but we consider that it is more likely to have been caused by a multiplication of persistent organisms which escaped leprosy treatment, for the following reasons -

(1) The dose of DDS is what we now consider an insufficient and low dose (WHO, 1977).

(2) A number of patients would not have been RFC if their records had been better scrutinized.

(3) In others, the original description and classification were not accurate.

(4) The date of inactivity on which the date of RFC should be based could not always be determined.

The number of relapsed patients discovered in this study is disturbing in view of the fact that so many report with new and often well-established nerve lesions. Very early lesions are reversible with treatment, but it is difficult to detect these early signs in relapsing patients. To differentiate old lesions from new lesions it is necessary to have good clinical records of the residual signs of leprosy at the time of RFC. Besides this clinical description of the skin, eyes, nerves and extremities of the patients, voluntary muscle testing (MRC War Memorandum, No. 7, 1943; Goodwin, 1968) and sensory testing (Naafs and Dagne, 1977) are extremely valuable. The results at the time of RFC can then be compared with the results at the time of check-up and relapse can be detected more accurately.

It is frightening that relapses of $30 \%$ in some groups are occurring in a wellstaffed and well-equipped centre like ALERT in Addis Ababa. Higher rates probably occur, but may pass unnoticed, in less sophisticated centres which nevertheless follow the WHO criteria.

Dapsone is a relatively safe drug which can be taken with hardly any sideeffects for years. However, from the leprosy control point of view a large number of "cured" patients in the programme represent a heavy work load. In order to diminish this work-load, patients should be RFC when it is virtually certain that they are indeed cured. Theoretically a $\mathrm{T}$ patient is healed after a certain, relatively short, period of treatment and continuation is then unnecessary. But as shown in this report, the rules for RFC as used in ALERT in 1974 are not sufficient to prevent a considerable number of relapses, about half of whom present with new disabilities.

Clinical information and statistical studies on relapses in leprosy from many different countries are needed in order to update international rules for RFC and to prevent grave disappointment to patients with leprosy and the doctors who treat them.

\section{Acknowledgements}

We are grateful to Dr H. W. Wheate for his valuable advice, and to the doctors of ALERT for their encouragement. This study was supported by the Netherlands Leprosy Relief Association and the Netherlands Government Technical Aid. 


\section{References}

Browne, S. G. (1965). Relapses in leprosy. Int. J. Lepr. 33, 273.

Cochrane, R. G. and Davey, T. F. (1964). Leprosy in Theory and Practice, p. 573. 2nd edit. Bristol: John Wright \& Sons Ltd.

Dharmendra (1976). Length of continued treatment of an inactive case of leprosy. Lepr. India 48, 212.

Erickson, P. T. (1950). Relapse following apparent arrest of leprosy by sulphone therapy. Publ. Hlth Rept 65, 1147. Reprinted in Int. J. Lepr. (1951) 19, 63.

Goodwin, C. S. (1968). The use of voluntary muscle test in leprosy neuritis. Lepr. Rev. 39, 209.

Kandaswamy, V. (1968). Relapse in leprosy in a mass control scheme. 9th International Leprosy Congress, London, Abstract 209.

Medical Research Council War Memorandum, No. 7 (1943). Aids to the Investigation of Peripheral Nerve Injuries. London: H.M. Stationery Office.

Naafs, B. and Dagne, T. (1977). A sensitive method in the follow up of nerve involvement. Int. J. Lepr. 45, 364.

Ramu, G. and Ramanujam, K. (1974). Relapse in borderline leprosy. Lepr. India 46, 19.

Rodriguez, J. N. (1958). Relapses after sulphone therapy in leprosy of the lepromatous type. 7 th International Congress of Leprology, Tokyo, p. 233.

WHO (1977). Technical Reports Series, 5th Report No.607, 24, referring to 4th Report, No. 459 , of 1970. 